\title{
Performance Analysis of Shunt Reactive Power Compensators
}

\author{
Taufik, Emili Schaefer \\ Electrical Engineering Department \\ Cal Poly State University \\ San Luis Obispo, CA 93407 USA \\ taufik@calpoly.edu
}

\author{
Makbul Anwari \\ Faculty of Electrical Engineering \\ Universiti Teknologi Malaysia \\ 81310 UTM Skudai, Malaysia \\ makbul@ieee.org
}

\author{
Mohammad Taufik \\ Department of Physics \\ Universitas Padjadjaran \\ Bandung 40132, Indonesia \\ mhtaufik@yahoo.com
}

\begin{abstract}
This paper offers comparative solutions for utility companies to solve the problem of voltage flicker in distribution systems. The solutions entail provision of shunt reactive compensation. Two solutions will be explored: the shunt capacitor and the Static VAR Compensator (SVC). Both solutions are modeled and simulated using PSCAD. Results will be compared by analyzing their performance when subjected to changes on the system, and problems that arise when connected to the system.
\end{abstract}

\section{Keywords—Static VAR, Power Quality}

\section{INTRODUCTION}

Power Electronics is known to be an enabling technology to convert electrical energy from one form to another. Applications of power electronics range from low power electronics found in portable devices to the extreme high power level such as those used in power system transmission and distribution [1]. However, utility companies have only begun to utilize the benefits of power electronics into power distribution and transmission systems. Often times, when power electronics are used, they are not utilized to their fullest ability. According to [2], the lack of fast voltage support has placed the U.S. grid at risk. The scarcity of VARs, especially dynamic VARs, was a contributor to the spread and cascade of the North American blackout of August, 14, 2003 [2]. Though this particular example concerns transmission systems, the lack of VAR support can be traced to distribution systems. VAR deficiencies on transmission lines arise when large air-conditioning units, irrigation motor loads and industrial motors are connected to distribution circuits [3].

Several times a day a large horsepower motor starts up on an industrial portion of a distribution circuit. The inrush current of the motor causes voltage flicker for the residential customers on the same distribution line as the industrial plant. Not only is the voltage variance an annoyance to the residential customers, but also could ultimately cause other motors on the circuit to trip offline due to low voltage resulting in large plant outages. Any unscheduled plant shutdown may result in lost productivity and material. A similar, yet less destructive, example of voltage flicker happens when a large residential air conditioning system flips on; the next-door neighbor may see a dimming of light.

The consequences of an industrial motor and the lack of VARs on a distribution system will be addressed in this paper. Furthermore, two methods used to lessen the impact a large induction motor has upon a small portion of an electrical distribution system upon start-up will also be discussed. The first method uses a more traditional solution, a shunt capacitor, while the second method applies a more modern approach by the use of power electronics.

In the conventional method, reactive compensation is achieved using a fixed capacitor to mitigate the start-up effects of the motor to the power system. In the modern method, power electronic controller is placed into the system to mitigate voltage disruptions caused by the starting of the motor. The benefits and disadvantages of using power electronics to solve the voltage problem will be presented in this paper.

For modeling the system, a software program called Power Systems Computer Aided Design (PSCAD) will be used to simulate the power system with the effects of the shunt capacitor and the power electronic controller. The basic power system model will first be developed with a large motor load. Once this is established, first the shunt capacitor, and later the SVC device will be implemented. A performance study that includes transient response, settling time, and stability will then be presented for both methods.

\section{VAR COMPENSATION METHODS}

A capacitor is the traditional VAR provider in the power system. The shunt capacitor delivers its own reactive power and reduces apparent power needed from the substation, increasing the power factor of the source that delivers power to the load. This in turn lessens the current flows from the substation, reduces the line losses and voltage drop, and allows more real power to be delivered on the line. The final result is improved efficiency and improved voltage regulation [4].

Static VAR Compensation (SVC) is another type of shunt compensation. It uses thyristor-switched reactors in parallel with capacitors. The thyristors are arranged in an anti-parallel fashion to allow current flow in both directions. The configuration allows for constant power factor correction as the reactive power changes. Reactive 
power is absorbed during light loading and supplied during heavy loading. The automatic control of SVC allocates the supply or consumption of VARs on the system with thyristor-controlled switches, thus minimizing voltage fluctuations and increasing line loadability. Figure 1 displays two typical SVC systems. The thyristor-controlled reactors (TCR) continuously monitor the reactive power on the system and compensate by varying the current flowing through the reactors. The thyristor-switched capacitors (TSC) switch the capacitor banks to the on or off position depending on how much compensation is needed. The alternating current filters (ACF) absorb harmonics generated by the TCR [5].

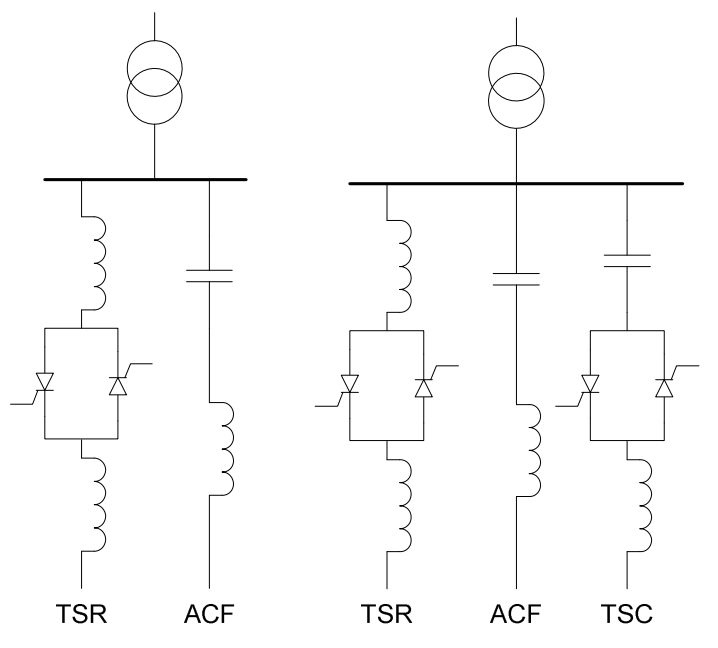

Figure 1. Typical SVC configuration

\section{DistRIBUTION SYSTEM MODELS}

To analyze performance both VAR compensation methods, models of the power distribution system were developed using PSCAD simulator. A system without the compensator is displayed in Figure 2 and is a simple radial form with a single machine and load. The motor model itself was derived using parameters in Table 1.

A sinusoidal source is used to model the voltage source of the distribution system from the substation. The machine external input parameters are $\mathrm{W}$ for speed control in per-unit, $\mathrm{S}$ for select, and $\mathrm{T}$ for torque in per unit. The machine is started in torque control which was chosen due to the transient response produced. In torque control mode, the motor starts up causing the motor current to run high and then decreases to a lower steady state value. The speed is calculated based on machine inertia, damping, and the input torque. The transformers are modeled as non-ideal in order to receive the most realistic response.

\section{Simulation Results}

Figure 3 depicts the motor current, load voltage, and load current. The focus is on the first five seconds which shows the effect of customer voltage and current levels due to motor inrush current. With a nominal line voltage of $120 \mathrm{~V}$, the load voltage shows that there is a 4-volt drop for several cycles after the motor starts. Initially, the first cycles dip to $111.5 \mathrm{~V}$ when the motor first starts up. Looking at the single phase to ground voltage drop and assuming that the flicker occurs on all three phases, the voltage deviates from the $120 \mathrm{~V}$ range for 2.5 seconds.

TABLE 1. SUMMARY OF MOTOR PARAMETERS

\begin{tabular}{|c|c|}
\hline \multicolumn{2}{|l|}{ Summary of Assumptions for Motor } \\
\hline \multicolumn{2}{|c|}{ Starting KVA per horse-power $=6.2 \mathrm{kVA} / \mathrm{hp}$} \\
\hline \multicolumn{2}{|l|}{ Starting power factor $=0.22$} \\
\hline \multicolumn{2}{|l|}{ Normal power factor $=0.8$} \\
\hline \multicolumn{2}{|l|}{$65 \%$ start on motor (2.2 multiplier) } \\
\hline \multicolumn{2}{|c|}{$\begin{array}{c}3 \text { wire } 21 \mathrm{kV} \mathrm{w} / \text { primary side voltage, } 21 \mathrm{kV} \text { line-line, and } \\
12.47 \mathrm{kV} \text { line-neutral }\end{array}$} \\
\hline \multicolumn{2}{|l|}{ EMTP Type 40 Parameters in per unit } \\
\hline Design Ratio & 1 \\
\hline Power Factor at Rated Load & 0.85 \\
\hline Efficiency at Rated Load & 0.82 \\
\hline Slip at Full Load & 0.025 \\
\hline Starting Current at Full Load & 5 \\
\hline Starting Torque at Full Volts/Full Load Torque & 4 \\
\hline Maximum Torque/Full Load Torque & 4 \\
\hline Number of Poles & 4 \\
\hline
\end{tabular}

The starting current reaches a maximum value of about $1050 \mathrm{~A}$ which is consistently 5 to 8 times the running current as expected. The load current also varies by a half amp, returning to the 15 -ampere range when the motor comes up to speed.

Figure 5 shows the system with the added shunt capacitor solution. A 0.6 MVAR shunt capacitor, 0.2 MVAR on each phase, is chosen because it suitably corrects the voltage sag for the duration of time when the motor starts up, but does not cause an over-voltage problem after the motor comes up to speed. At first, this seemed to be an acceptable solution, but under further investigation this is not the best solution because the capacitor should not be left on the line when compensation is not needed. The capacitor should not remain connected to the system, because this may cause the circuit to become overcompensated which is not desirable.

Figure 4 shows the characteristics of voltage and current waveforms due to the shunt capacitor. The voltage drop is now $2.75 \mathrm{~V}$. This value is significantly less than the uncompensated line. This design is therefore better, during motor start-up than the uncompensated line because the flicker is present for a shorter amount of time. The voltage is still below the normal $120 \mathrm{~V}$-range for over 2 seconds or 120 cycles. The drop value compares to the calculated value of $1.79 \mathrm{~V}$. There is a large current spike on the load waveform for one cycle, lasting for less than a tenth of a second and the fact the voltage does not peak very high is fairly trivial. 


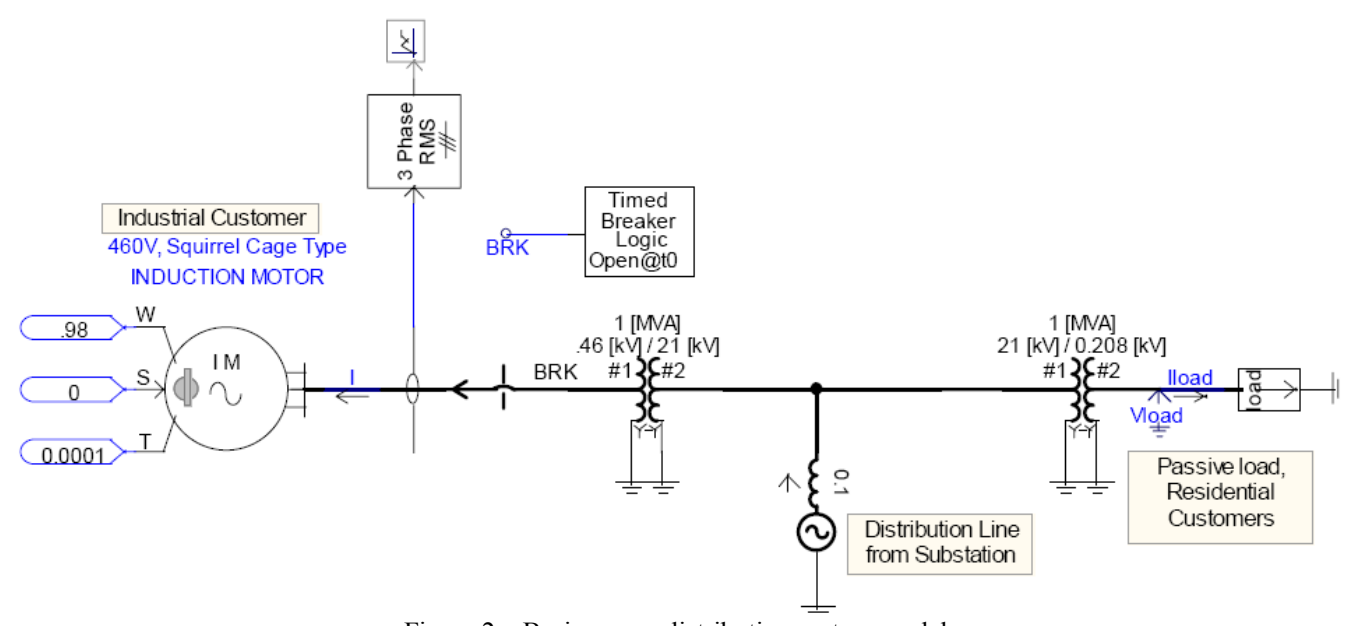

Figure 2. Basic power distribution system model

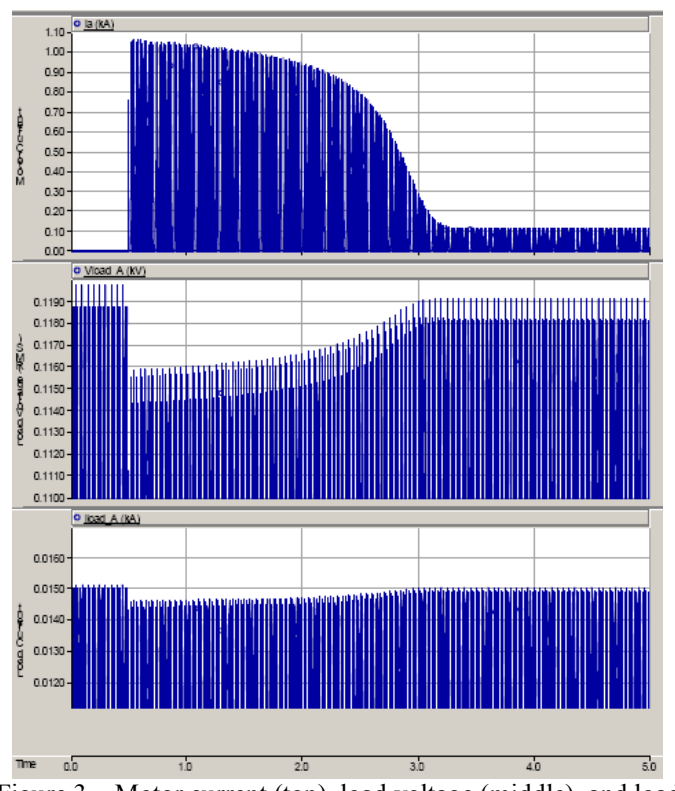

Figure 3. Motor current (top), load voltage (middle), and load current (bottom) in basic system

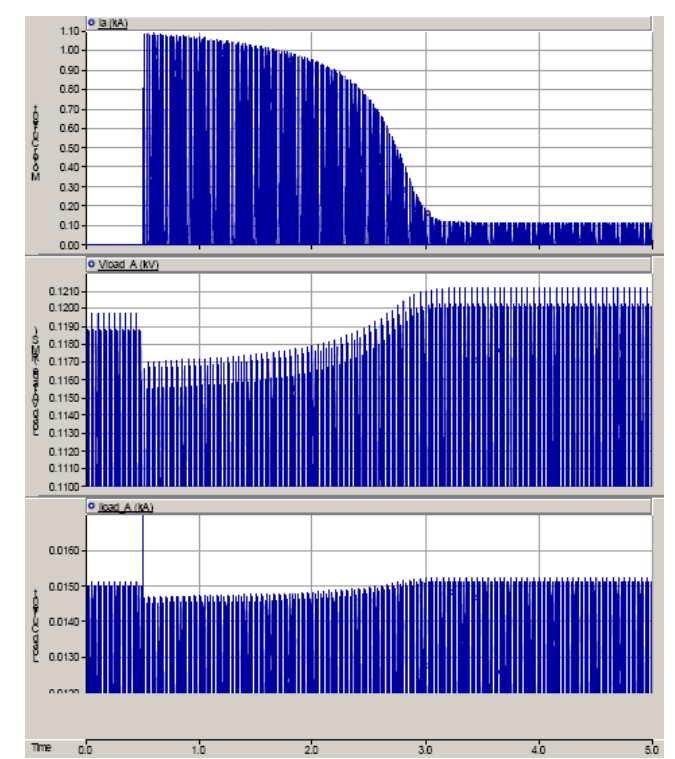

Figure 4. Motor current (top), load voltage (middle), and load current (bottom) in system with shunt capacitor

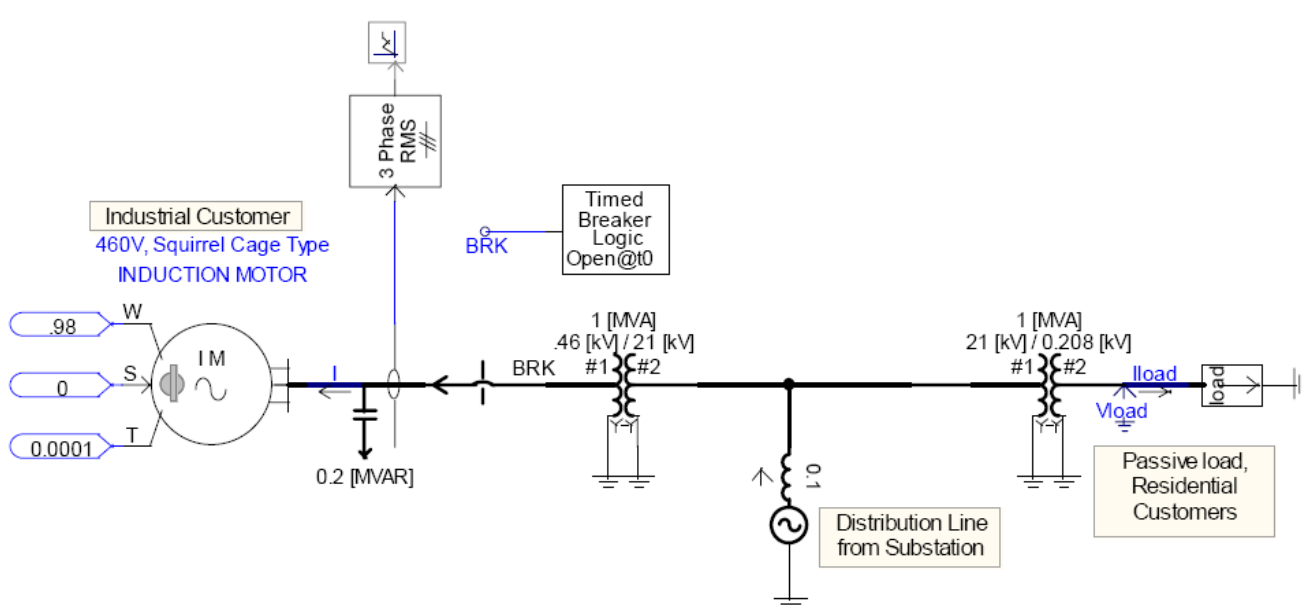

Figure 5. Power distribution system model with shunt capacitor 


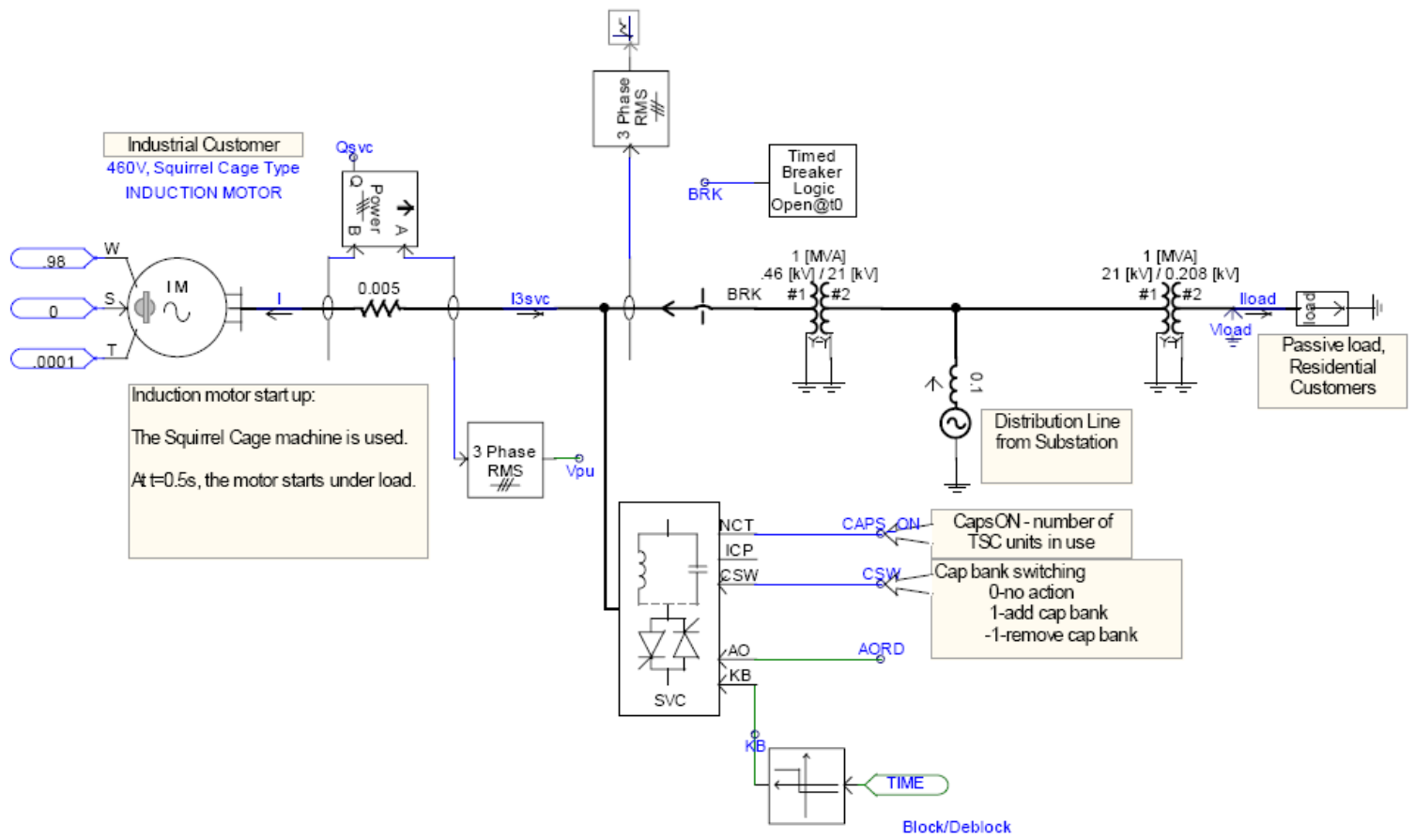

Figure 6. Power distribution system model with SVC

Figure 7 shows the characteristics of the voltage and current waveforms with SVC and the inrush current of the motor. This solution shows a voltage drop of virtually zero volts. This is significantly less than both the uncompensated line and the system with the shunt capacitor. The SVC design forces the motor current to stay at a $215 \mathrm{~A}$ level, which is still below the rated running value of the motor. A non-varying nominal voltage measured at the load location is also the desired result. The optimum SVC system produces no voltage drop at the load, which this model shows.

The same three models described previously were further tested under the condition that the torque of motor load is changed drastically. Results of the simulations once again show that the SVC system's performance is superior in suppressing the impact of the large starting current of the motor. The SVC system only shows a very slight raise in residential customer voltage from the nominal $120 \mathrm{~V}$ level when the motor current is at its highest point. Both the load voltage and current remain undisturbed. However, when this same scenario is applied to either the uncompensated line or the shunt capacitor line, the residential customers, once again see voltage stability problems.

In all cases or tests, simulations of the three models indicate that the SVC. The benefit to SVC is that it is continuously controllable with power electronics as opposed to the mechanically controllable shunt capacitor. In the case where the load motor is only turned on and off several times a day, a shunt capacitor solution is appropriate. This is because the motor characteristics are known and the effects are easily predicted, so a mechanical switch can be programmed to mitigate the voltage flicker. However, in the case that several large motors are online and a high-power event happens every several minutes at unknown intervals, the SVC system is a more appropriate solution to monitor the reactive power.

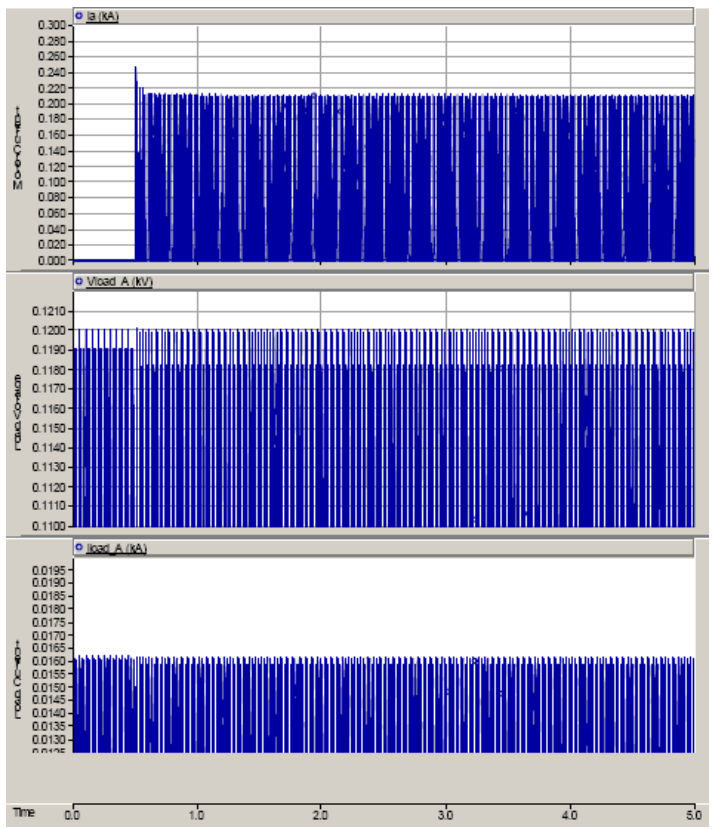

Figure 7. Motor current (top), load voltage (middle), and load current (bottom) in system with SVC 
In a situation where the response of the motor current and load voltage can be easily predicted and the mechanical switch can be accurately programmed, a shunt capacitor solution with disconnect to the system is an appropriate solution. However, if there is an inflated amount of random high-powered activity on the line, a fast-acting and continuous device should be employed.

\section{CONCLUSION}

This paper describes the development of a power system distribution model used to test performance of two reactive compensation methods. The reactive compensators were used to address issues related to voltage flicker due to inrush current of large motor load. The model including the compensator models were built using the PSCAD software. Simulations of the model show that the shunt capacitor solution improved the voltage quality at the residential load with only one simple motor. Though flicker was still apparent for several cycles, voltage did not dip to an unacceptable level; therefore, flicker was not noticed at the load. However, when a large amount of random activity representing several motors was considered, the power system model with SVC demonstrated superior results with the voltage quality seen at the customer load.

Power quality is as important to utilities as it is to the customer. As power system becomes more complex, modeling of the power system using software such as PSCAD such as presented in this paper will become very useful in analyzing system's operation and performance.

\section{REFERENCES}

[1]. Edris, A., Power Electronic-Based Controllers at Technological Crossroad, EPRI Journal Online. Palo Alto, August 21, 2002.

[2]. Bradshaw, D. T., It's Time to Address the Critical Issue of VAR Compensation, Transmission and Distribution World, Premedia, Inc., April 1, 2004.

[3]. Hsu, S., Using a Static Var Compensator to Balance a Distribution System, IEEE Transactions on Industry Applications, Vol. 35, No.5, September/October 1999.

[4]. Glover, J. D. and Mulukutla S. S., Power System Analysis and Design, $3^{\text {rd }}$ ed., Brooks/Cole, 2002.

[5]. Toshiba Corporation \& Toshiba International Corp., SVC Operation Principles, Sydney, 2001. 